\title{
Characterization and Zoonotic Potential of Uropathogenic Escherichia coli Isolated from Dogs
}

\author{
Nam, Eui-Hwa, Sungjin Ko, Joon-Seok Chae*, and Cheol-Yong Hwang* \\ The Research Institute for Veterinary Science, College of Veterinary Medicine, Seoul National University, Seoul 151-742, Korea
}

Received: September 19, 2012 / Revised: November 9, 2012 / Accepted: November 20, 2012

The aim of this study was to investigate the characteristics of canine uropathogenic Escherichia coli (UPEC) and the interaction between canine UPEC and human bladder epithelial cells. Ten $E$. coli isolates collected from dogs with cystitis were analyzed for antimicrobial resistance patterns, the presence of virulence factors, and biofilm formation. The ability of these isolates to induce cytotoxicity, invade human bladder epithelial cells, and stimulate an immune response was also determined. We observed a high rate of antimicrobial resistance among canine UPEC isolates. All virulence genes tested (including adhesins, iron acquisition, and protectin), except toxin genes, were detected among the canine UPEC isolates. We found that all isolates showed varying degrees of biofilm formation (mean, 0.26 ; range, 0.07 to 0.82 ), using a microtiter plate assay to evaluate biofilm formation by the isolates. Cytotoxicity to human bladder epithelial cells by the canine UPEC isolates increased in a time-dependent manner, with a $56.9 \%$ and $36.1 \%$ reduction in cell viability compared with the control at 6 and $9 \mathrm{~h}$ of incubation, respectively. We found that most canine UPEC isolates were able to invade human bladder epithelial cells. The interaction between these isolates and human bladder epithelial cells strongly induced the production of proinflammatory cytokines such as IL-6 and IL-8. We demonstrated that canine UPEC isolates can interact with human bladder epithelial cells, although the detailed mechanisms remain unknown. The results suggest that canine UPEC isolates, rather than dogspecific pathogens, have zoonotic potential.

\footnotetext{
* Corresponding authors

C.-Y.H.

Phone: +82-2-880-1281; Fax: +82-2-880-1281;

E-mail: cyhwang@snu.ac.kr

J.S.C.

Phone: +82-2-880-1279; Fax: +82-2-873-1213;

E-mail: jschae@snu.ac.kr
}

Key words: Dog, human bladder epithelial cells, uropathogenic Escherichia coli

Urinary tract infections (UTIs), including cystitis and pyelonephritis, are one of the most common infectious diseases of humans and domestic animals [5, 37]. Of the numerous bacteria that can cause UTIs, Escherichia coli is the most frequent infectious agent and is responsible for $>80 \%$ of all UTIs [7, 31]. Commensal E. coli in the intestinal tract colonizes the vaginal and periuretheral tissues, ascend into the bladder, and cause a UTI [7, 32].

$E$. coli is responsible for a wide range of human and animal diseases, including UTIs, newborn meningitis, and septicemia $[22,28]$. A previous study on the relationships between human and canine $E$. coli isolates suggested that these isolates exhibit host specificity with respect to virulence factors [15]. However, several studies have recently shown that $E$. coli might have zoonotic potential, due to the considerable commonality observed between human and animal E. coli isolates from UTIs [10, 12].

The pathogenic potential of uropathogenic E. coli (UPEC) is thought to be dependent on the host and bacterial factors contributing to invasion into bladder epithelial cells [16]. Bladder epithelial cells play a significant role in the innate immune response during UTIs $[7,13]$. The immune responses to UTIs by UPEC are initiated when infecting bacteria reach the bladder through progressive colonization and multiply rapidly in the urine, which induces the production of proinflammatory cytokines [27, 29].

This study was conducted to investigate the genotypic and phenotypic characteristics of clinical E. coli isolated from dogs in Korea with clinical signs of cystitis. Furthermore, to gather knowledge on the possible zoonotic aspect of canine UPEC, the interaction between canine UPEC isolates and human T24 bladder epithelial cells was evaluated in vitro. 


\section{Materials And Methods}

\section{Bacterial Isolates}

The ten E. coli isolates included in this study were obtained from the urine of $10 \mathrm{dogs}$ with cystitis before administering antibiotics at the Veterinary Medical Teaching Hospital of Seoul National University (Korea) in 2008. Urine samples were collected aseptically from dogs by cystocentesis. After collection, samples were cultured overnight at $37^{\circ} \mathrm{C}$ on blood agar plates. All isolates were identified as $E$. coli using standard biochemical tests and the Vitek 2 system (bioMérieux, Hazelwood, MO, USA). The isolated bacteria were stored at $-80^{\circ} \mathrm{C}$ in LB broth with $50 \%$ glycerol until further analysis.

\section{Antimicrobial Susceptibility Testing}

The minimum inhibitory concentrations (MICs) of a range of antibiotics were determined for the E. coli isolates using the VITEK 2 system according to the manufacturer's guidelines. The MIC results were interpreted according to the guidelines of the National Committee for Clinical Laboratory Standards [4].

\section{Virulence Factors}

The isolates were screened for the presence of virulence genes by polymerase chain reaction (PCR). The primer sequences for each virulence factor gene are shown in Table 1. E. coli genomic DNA was isolated from overnight cultures using the DNeasy Blood and

Table 1. Primers used for virulence gene detection.

\begin{tabular}{|c|c|c|c|}
\hline Gene & Description & Primer sequence $\left(5^{\prime}-3^{\prime}\right)$ & Size (bp) \\
\hline \multicolumn{4}{|l|}{ Adhesins } \\
\hline \multirow{2}{*}{$a f a / d r a$} & \multirow[t]{2}{*}{ Dr antigen-specific fimbrial and afimbrial adhesin } & F: GCTGGGCAGCAAACTGATAACTCTC & 750 \\
\hline & & R: CATCAAGCTGTTTGTTCGTCCGCCG & \\
\hline \multirow[t]{2}{*}{$\mathrm{fimH}$} & \multirow[t]{2}{*}{ Type 1 fimbriae } & F: TCGAGAACGGATAAGCCGTGG & 508 \\
\hline & & R: GCAGTCACCTGCCCTCCGGTA & \\
\hline \multirow[t]{2}{*}{ papC } & \multirow[t]{2}{*}{ Central region of $\mathrm{P}$ pili } & F: GACGGCTGTACTGCAGGGTGTGGCG & 328 \\
\hline & & R: ATATCCTTTCTGCAGGGATGCAATA & \\
\hline \multirow[t]{2}{*}{$s f a$} & \multirow[t]{2}{*}{ Central region of S fimbriae } & F: GTGGATACGACGATTACTGTG & 242 \\
\hline & & R: CCGCCAGCATTCCCTGTATTC & \\
\hline \multirow[t]{2}{*}{ foc $G$} & Central region of $\mathrm{F} 1$ & F: CAGCACAGGCAGTGGATACGA & 362 \\
\hline & C fimbriae & R: GAATGTCGCCTGCCCATTGCT & \\
\hline \multirow[t]{2}{*}{ papGI } & \multirow[t]{2}{*}{ Class I P pili } & F: TCGTGCTCAGGTCCGGAATTT & 461 \\
\hline & & R: TGGCATCCCCCAACATTATCG & \\
\hline \multirow[t]{2}{*}{ papGII } & \multirow[t]{2}{*}{ Class II P pili } & F: GGGATGAGCGGGCCTTTGAT & 190 \\
\hline & & R: CGGGCCCCCAAGTAACTCG & \\
\hline \multirow[t]{2}{*}{ papGIII } & \multirow[t]{2}{*}{ Class III P pili } & F: CATGGCTGGTTGTTCCTAAACAT & 421 \\
\hline & & R: TCCAGAGACTGTGCAGAAGGAC & \\
\hline \multicolumn{4}{|l|}{ Toxins } \\
\hline \multirow[t]{2}{*}{ cnfl } & \multirow[t]{2}{*}{ Cytotoxic necrotizing factor 1} & F: GAACTTATTAAGGATAGT & 533 \\
\hline & & R: CATTATTTATAACGCTG & \\
\hline \multirow[t]{2}{*}{ hlyA } & \multirow[t]{2}{*}{$\alpha$-Hemolysin } & F: AACAAGGATAAGCACTGTTCTGGCT & 1,177 \\
\hline & & R: ACCATATAAGCGGTCATTCCCGTCA & \\
\hline \multirow[t]{2}{*}{$v t 1$} & \multirow[t]{4}{*}{ Verocytotoxin } & F: AAGTTGCAGCTCTCTTTGAATA & 364 \\
\hline & & R: TGCAAACAAATTATCCCCTGAG & \\
\hline \multirow[t]{2}{*}{$v t 2$} & & F: GGGCAGTTATTTTGCTGTGGA & 515 \\
\hline & & R: GTATCTGCCTGAAGCGTAA & \\
\hline \multicolumn{4}{|c|}{ Iron acquisition } \\
\hline \multirow[t]{2}{*}{$i u c D$} & \multirow[t]{2}{*}{ Aerobactin siderophore } & F: TACCGGATTGTCATATGCAGACCGT & 602 \\
\hline & & R: AATATCTTCCTCCAGTCCGGAGAAG & \\
\hline \multicolumn{4}{|l|}{ Protectins } \\
\hline kpsMTII & Group II capsular polysaccharide synthesis & F: GCGCATTTGCTGATACTGTTG & 272 \\
\hline & & R: CATCCAGACGATAAGCATGAGCA & \\
\hline Miscellaneo & & & \\
\hline usp & Uropathogen-specific protein & F: ACATTCACGGCAAGCCTCAG & 440 \\
\hline & & R: AGCGAGTTCCTGGTGAAAGC & \\
\hline eae & Intimin & F: GACCCGGCACAAGCATAAGG & 384 \\
\hline & & R: CCACCTGCAGCAACAAGAGC & \\
\hline
\end{tabular}


Tissue Kit (Qiagen GmbH, Hilden, Germany) according to the manufacturer's instructions. PCRs were performed in a $25 \mu \mathrm{l}$ reaction mixture containing $1.5 \mathrm{U}$ of Taq DNA polymerase (TaKaRa, Otsu, Shiga, Japan), $2.5 \mu 1$ of $10 \times$ reaction buffer, $2 \mu 1$ of $2.5 \mathrm{mM}$ dNTP mixture, $10 \mathrm{pmol}$ of the forward and reverse primers, and $0.5 \mu \mathrm{l}$ of DNA template. The PCR conditions were an initial denaturation at $94^{\circ} \mathrm{C}$ for $5 \mathrm{~min}$, followed by 35 cycles of $94^{\circ} \mathrm{C}$ for $1 \mathrm{~min}, 58^{\circ} \mathrm{C}$ for $1 \mathrm{~min}$, and $72^{\circ} \mathrm{C}$ for $1 \mathrm{~min}$, and then a final extension at $72^{\circ} \mathrm{C}$ for $5 \mathrm{~min}$. The PCR products were directly sequenced using an automatic sequencer (ABI 3730XL; Applied Biosystems, Foster City, CA, USA).

\section{Biofilm Formation Assay}

Biofilm formation of $E$. coli isolates was assessed using a microtiter plate assay. Bacteria were grown for $24 \mathrm{~h}$ at $37^{\circ} \mathrm{C}$ in $96-$-well microtiter plates (SPL Life Science, Seoul, Korea) using $100 \mu$ of bacterial culture per well. The bacterial cultures were removed and the plates were washed three times with PBS. Biofilms were stained with $1 \%$ crystal violet for $20 \mathrm{~min}$. Plates were washed three times with PBS and air dried. After solubilization of the crystal violet with 95\% ethanol, the biofilm was quantified by an enzyme-linked immunosorbent assay (ELISA) reader (Bio-Rad, Munich, Germany) at $570 \mathrm{~nm}$. The nonpathogenic E. coli strain DH5 $\alpha$ served as a negative control for biofilm formation. All experiments were performed in triplicate, and the results are reported as the mean and standard deviation.

\section{Cytotoxicity Assay}

The assessment of cytotoxicity of the $E$. coli isolates against human bladder epithelial cells was carried out using a modified watersoluble tetrazolium salt (WST-1) assay (EZ-Cytox Cell Viability Assay Kit; Daeil Lab Service, Seoul, Korea) as described previously [20]. The human T24 bladder epithelial cell line (derived from a bladder carcinoma; KCLB 30004) was purchased from the Korean Cell Line Bank (Seoul, Korea). T24 cells were seeded at $1 \times 10^{4}$ cells/well in 96-well microtiter plates containing RPMI 1640 medium (Gibco BRL, Gaithersburg, MD, USA) supplemented with $10 \%$ heat-inactivated fetal bovine serum (Sigma, St. Louis, MO, USA) at $37^{\circ} \mathrm{C}$ in $5 \% \mathrm{CO}_{2}$. The cell monolayers were infected with E. coli isolates at a multiplicity of infection (MOI) of 1:100 for 3, 6, and $9 \mathrm{~h}$. After the incubation, $10 \mu \mathrm{l}$ of EZ-Cytox Reagent was added to the culture wells, and the cultures were incubated for an additional $1 \mathrm{~h}$ at $37^{\circ} \mathrm{C}$. Absorbance was measured with an ELISA reader at $540 \mathrm{~nm}$. Results are expressed as a percentage of the control culture conditions, and data are presented as the mean and standard deviation of triplicate determinations.

\section{Invasion Assay}

The ability of $E$. coli isolates to invade T24 cells was assayed with an antibiotic protection assay, as described previously [21, 36]. T24 cells $\left(1 \times 10^{5}\right.$ cells/well) in 12-well tissue culture plates (Costar, Cambridge, MA, USA) were infected with E. coli isolates at a MOI of 1:10 and incubated for $4 \mathrm{~h}$. After infection, cell monolayers were washed twice with PBS, and fresh cell culture medium containing $100 \mu \mathrm{g} / \mathrm{ml}$ meropenum was added for an additional $2 \mathrm{~h}$ to kill extracellular bacteria. After washing with PBS, serial dilutions of cells were plated on brain-heart infusion agar plates to determine the total number of intracellular bacteria. Noninvasive E. coli $\mathrm{DH} 5 \alpha$ was used as the negative control. Invasion was expressed as the total number of $\mathrm{CFU} / \mathrm{ml}$. All assays were conducted in duplicate and repeated independently at least three times.

\section{Real-Time Polymerase Chain Reaction}

T24 cells were seeded in 6-well plates (Costar) at $3 \times 10^{5}$ cells/well to assess cytokine secretion. The cells were then infected with $E$. coli isolates at a MOI of 100 for $4 \mathrm{~h}$. Total RNA was isolated from cultured cells with TRIzol reagent (Molecular Research Center, Cincinnati, OH, USA) according to the manufacturer's instructions. cDNA was synthesized from total RNA using the PrimeScript First Strand cDNA Synthesis Kit (TaKaRa, Tokyo, Japan). Real-time PCR was performed with a StepOne Plus Real-Time PCR system (Applied Biosystems) in $10 \mu \mathrm{l}$ containing $0.5 \mu \mathrm{l}$ of template cDNA, SYBR Premix Ex Taq (TaKaRa), and 10 pmol of forward and reverse primers. The following oligonucleotide primers were used: interleukin (IL)-6, forward, 5'-TCCAGAACAGATTTGAGAGTAGTG-3' and reverse, 5'-GCATTTGTGGTTGGGTCAGG-3'; IL-8, forward, 5'ATGACTTCCAAGCTGGCCGTGGCT-3' and reverse, 5'-TCT CAGCCCTCTTCAAAAACTTCTC-3'; glyceraldehyde-3'-phosphate dehydrogenase (GAPDH), forward, 5'-TGCACCACCAACTGC TTAGC-3' and reverse, 5'-GGCATGGACTGTGGTCATGAG-3'. The thermal cycling conditions were $2 \mathrm{~min}$ at $50^{\circ} \mathrm{C}$ and $10 \mathrm{~min}$ at $95^{\circ} \mathrm{C}$, followed by 45 cycles of $15 \mathrm{~min}$ at $90^{\circ} \mathrm{C}$ and $1 \mathrm{~min}$ at $60^{\circ} \mathrm{C}$. Relative gene expression was determined using the $\Delta \Delta \mathrm{C}_{\mathrm{T}}$ method with GAPDH as the internal control.

\section{Statistical Analysis}

Results are expressed as means \pm standard deviations (SD). Results were compared by Student's $t$-test, using the Microsoft Excel software. $P$-values $<0.05$ were considered significant.

\section{RESULTS}

\section{Canine UPEC Characteristics}

We analyzed $10 \mathrm{E}$. coli clinical isolates from the urine of dogs with cystitis. The MICs of each antimicrobial agent for all canine UPEC isolates are summarized in Table 2. Of the penicillins, ampicillin showed the lowest activity (MIC $8 \mu \mathrm{g} / \mathrm{ml} ; 12.5 \%$ susceptible) and piperacillin/tazobactam the highest activity (MIC $\leq 16 \mu \mathrm{g} / \mathrm{ml} ; 100 \%$ susceptible) against all canine UPEC isolates. Despite the high antimicrobial activity of the fluoroquinolones against the $E$. coli isolates, a high resistance rate to ciprofloxacin was observed among all isolates studied (MIC $\leq 0.25 \mu \mathrm{g} / \mathrm{ml}$; $40 \%$ susceptible). Of the cephalosporins tested, cefazolin was the least effective (MIC $\leq 4 \mu \mathrm{g} / \mathrm{ml} ; 25 \%$ susceptible), and cefepim was the most effective cephalosporin (MIC $\leq$ $1 \mu \mathrm{g} / \mathrm{ml} ; 80 \%$ susceptible) against all isolates. The carbapenem antibiotics imipenem and meropenem were very active against all isolates ( $\mathrm{MIC} \leq 2 \mu \mathrm{g} / \mathrm{ml}$ and $\leq 0.25 \mu \mathrm{g} / \mathrm{ml}$, respectively; $100 \%$ susceptible).

The isolated canine UPEC strains were tested for the presence of virulence-associated genes using PCR to detect 16 genes (Table 3 ). The $\mathrm{fimH}$ adhesion gene was the most common virulence factor detected (six isolates), followed by papC (three isolates), papGII (two isolates), 
Table 2. Minimum inhibitory concentration (MIC) values of canine uropathogenic $E$. coli isolates determined using the Vitek 2 system.

\begin{tabular}{|c|c|c|c|c|c|c|c|c|c|c|}
\hline \multirow{2}{*}{ Antimicrobial agent } & \multicolumn{10}{|c|}{ MIC $(\mu \mathrm{g} / \mathrm{ml})$ for isolates } \\
\hline & 1 & 2 & 3 & 4 & 5 & 6 & 7 & 8 & 9 & 10 \\
\hline Amikacin & $\leq 2$ & $\leq 2$ & $\leq 2$ & $\leq 2$ & $\leq 2$ & $\leq 2$ & $\geq 64$ & $\leq 2$ & 4 & $\leq 2$ \\
\hline Ampicillin & ND & ND & $\geq 32$ & $\geq 32$ & $\geq 32$ & $\geq 32$ & $\geq 32$ & 16 & $\geq 32$ & 8 \\
\hline Aztreonam & $\leq 1$ & $\leq 1$ & $\leq 1$ & 4 & 8 & 16 & 2 & $\leq 1$ & 16 & $\leq 1$ \\
\hline Cefazolin & ND & ND & $\geq 64$ & $\geq 64$ & $\geq 64$ & $\geq 64$ & $\geq 64$ & $\leq 4$ & $\geq 64$ & $\leq 4$ \\
\hline Cefepime & $\leq 1$ & $\leq 1$ & $\leq 1$ & 2 & $\leq 1$ & $\leq 1$ & $\leq 1$ & $\leq 1$ & 4 & $\leq 1$ \\
\hline Cefotaxime & $\leq 1$ & $\leq 1$ & 32 & $\geq 64$ & 8 & 8 & 4 & $\leq 1$ & $\geq 64$ & $\leq 1$ \\
\hline Ceftazidime & $\leq 1$ & $\leq 1$ & $\leq 1$ & $\leq 1$ & 32 & $\geq 64$ & 8 & $\leq 1$ & 16 & $\leq 1$ \\
\hline Ciprofloxacin & $\leq 0.25$ & $\leq 0.25$ & $\geq 4$ & $\geq 4$ & $\geq 4$ & $\geq 4$ & $\geq 4$ & 2 & $\geq 4$ & $\leq 0.25$ \\
\hline Gentamicin & $\leq 1$ & $\leq 1$ & $\leq 1$ & $\leq 1$ & $\geq 16$ & $\leq 1$ & $\geq 16$ & $\leq 1$ & $\geq 16$ & $\leq 1$ \\
\hline Imipenem & $\leq 1$ & $\leq 1$ & $\leq 1$ & $\leq 1$ & $\leq 1$ & $\leq 1$ & 2 & $\leq 1$ & $\leq 1$ & $\leq 1$ \\
\hline Levofloxacin & 1 & $\leq 0.25$ & ND & ND & ND & ND & ND & ND & ND & ND \\
\hline Meropenem & $\leq 0.25$ & $\leq 0.25$ & $\leq 0.25$ & $\leq 0.25$ & $\leq 0.25$ & $\leq 0.25$ & $\leq 0.25$ & $\leq 0.25$ & $\leq 0.25$ & $\leq 0.25$ \\
\hline Minocycline & $\leq 1$ & 8 & ND & ND & ND & ND & ND & ND & ND & ND \\
\hline Netilmicin & $\leq 1$ & $\leq 1$ & ND & ND & ND & ND & ND & ND & ND & ND \\
\hline Piperacillin & $\leq 4$ & $\leq 4$ & $\geq 128$ & $\geq 128$ & $\geq 128$ & 32 & 64 & $\leq 4$ & $\geq 128$ & $\leq 4$ \\
\hline Piperacillin/Tazobactam & $\leq 4$ & $\leq 4$ & $\leq 4$ & $\leq 4$ & 8 & $\leq 4$ & 16 & $\leq 4$ & $\leq 4$ & $\leq 4$ \\
\hline Tetracycline & ND & ND & 2 & 2 & $\geq 16$ & $\leq 1$ & $\geq 16$ & 8 & 2 & 2 \\
\hline Ticarcillin & $\leq 8$ & $\leq 8$ & ND & ND & ND & ND & ND & ND & ND & ND \\
\hline Ticarcillin/Clavulanic acid & $\leq 8$ & $\leq 8$ & 4 & 4 & $\geq 32$ & $\geq 32$ & $\geq 32$ & 4 & 4 & 4 \\
\hline Tobramycin & $\leq 1$ & $\leq 1$ & $\leq 1$ & $\leq 1$ & 4 & $\leq 1$ & 4 & $\leq 1$ & 8 & $\leq 1$ \\
\hline Trimethoprim/Sulfamethoxazole & $\leq 20$ & $\leq 20$ & $\leq 20$ & $\leq 20$ & $\geq 320$ & $\leq 20$ & $\geq 320$ & $\leq 20$ & $\geq 320$ & $\leq 20$ \\
\hline
\end{tabular}

ND, no data, because no breakpoints are defined.

and $f o c G$ and papGIII (one isolate). None of the isolates showed genes encoding other adhesins (afa, sfa, or papGI). Additionally, usp, kpsMTII, and iucD were found in four, four, and three of all E. coli isolates, respectively. Toxin genes, such as $c n f l$ and $h l y A$ and verotoxins ( $v t l$ and $v t 2)$ or eae were not detected in any of the isolates. The number of virulence genes detected in $E$. coli isolates was 1-7 among the 16 genes tested, with the exception of two isolates.

The ability of each isolate to form a biofilm was assessed using a microtiter plate assay (Fig. 1). All canine UPEC isolates tested with nonpathogenic E. coli DH5 $\alpha$ were able to form biofilms to varying degrees. Most clinical isolates had a lower ability to form biofilms than that of $E$. coli DH5 $\alpha$ (control), although biofilm formation by two isolates was significantly greater than that by the control $(p<0.05)$. The levels of biofilm formation observed in the microtiter plate assay ranged from 0.07 to 0.82 . The mean optical density at $570 \mathrm{~nm}$ of the 10 isolates was 0.26 \pm 0.03 (mean $\pm \mathrm{SD})$.

Influence of $\boldsymbol{E}$. coli on Human Bladder Epithelial Cells The cytotoxic and invasion abilities of the canine clinical UPEC isolates were tested on T24 human bladder epithelial cells. The toxicity of canine UPEC isolates to
Table 3. Distribution of virulence genes determined by PCR in canine uropathogenic E. coli isolates.

\begin{tabular}{|c|c|c|c|c|c|c|c|c|c|c|}
\hline \multirow{2}{*}{$\begin{array}{l}\text { Virulence } \\
\text { gene }\end{array}$} & \multicolumn{10}{|c|}{ Isolates } \\
\hline & 1 & 2 & 3 & 4 & 5 & 6 & 7 & 8 & 9 & 10 \\
\hline afa/dra & - & - & - & - & - & - & - & - & - & - \\
\hline fimH & + & - & - & - & - & + & + & + & + & + \\
\hline papC & + & - & - & - & - & - & - & + & - & + \\
\hline$s f a$ & - & - & - & - & - & - & - & - & - & - \\
\hline foc $G$ & - & - & - & - & - & - & - & + & - & - \\
\hline papGI & - & - & - & - & - & - & - & - & - & - \\
\hline papGII & + & - & - & - & - & - & - & + & - & - \\
\hline papGIII & - & - & - & - & - & - & - & - & - & + \\
\hline cnfl & - & - & - & - & - & - & - & - & - & - \\
\hline hlyA & - & - & - & - & - & - & - & - & - & - \\
\hline$v t 1$ & - & - & - & - & - & - & - & - & - & - \\
\hline$v t 2$ & - & - & - & - & - & - & - & - & - & - \\
\hline iисD & + & - & - & - & + & - & - & + & - & + \\
\hline kpsMTII & + & + & - & - & - & - & - & + & - & + \\
\hline usp & + & - & - & - & - & - & + & + & - & + \\
\hline eae & - & - & - & - & - & - & - & - & - & - \\
\hline
\end{tabular}

+, positive; -, negative.

T24 cells using the WST-1 colorimetric assay is shown in Fig. 2. The number of viable T24 cells decreased 


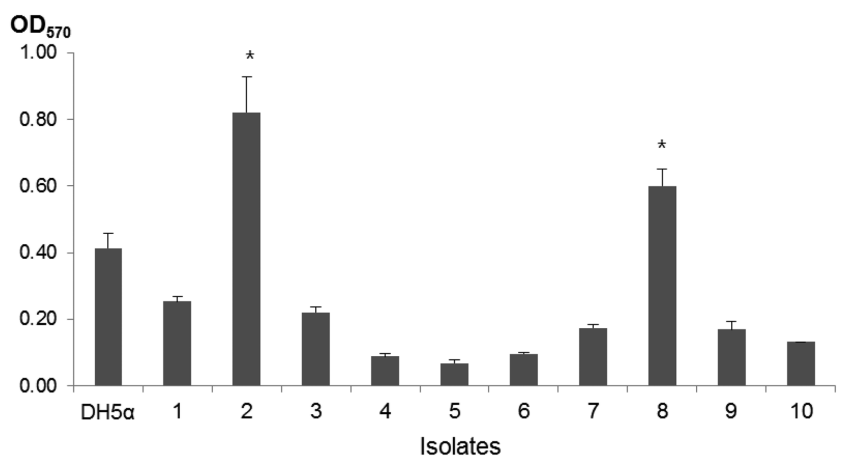

Fig. 1. Biofilm formation abilities of canine uropathogenic $E$. coli isolates measured by microtiter plate assay (crystal violet destaining). Two ( 2 and 8$)$ of the 10 isolates formed significantly more biofilm compared with DH5 $\alpha$ (control) $(*, p<0.05$, Student's $t$-test). Results are means \pm standard deviations (error bars) of triplicate assays.

significantly in a time-dependent manner. However, canine UPEC isolates had no toxic effects on T24 cells during the first $3 \mathrm{~h}$ of the incubation. In the presence of canine UPEC, cell viability compared with that in the negative control decreased to $56.9 \%$ and $36.1 \%$ at 6 and $9 \mathrm{~h}$ of incubation, respectively. At different MOIs of 10 and 100, cell viability was similarly altered by canine UPEC at different time points (data not shown). Thus, the increasing cytotoxicity trend was time-dependent rather than dose-dependent.

The invasive activity of canine UPEC into T24 cells was examined using an antibiotic protection assay to quantify intracellular bacteria (Fig. 3). The number of invading bacteria in the canine UPEC isolates was 10-100 times higher than the number of noninvading E. coli $\mathrm{DH} 5 \alpha$ (used as a negative control), with the exception of two isolates. The mean invasion index of canine UPEC isolates was $(64.17 \pm 19.14) \times 10^{2} \mathrm{CFU} / \mathrm{ml}$.

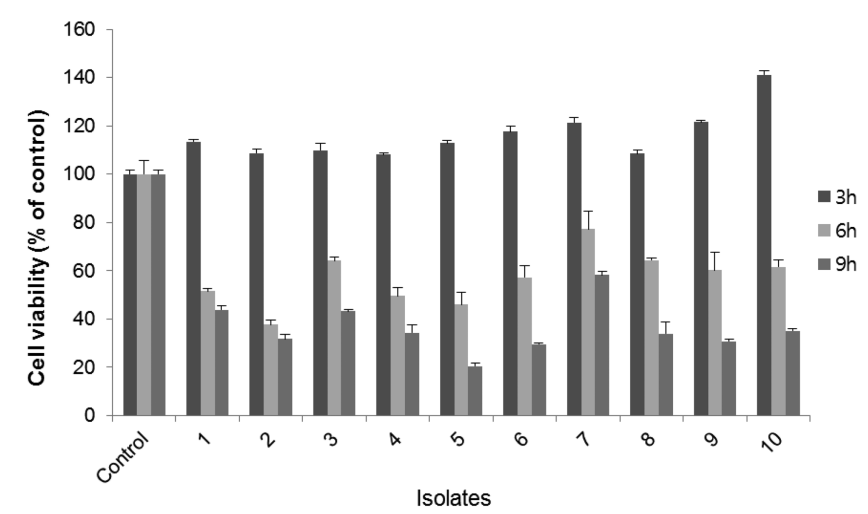

Fig. 2. Cytotoxicity of canine uropathogenic E. coli isolates to human T24 bladder epithelial cells.

T24 cells were infected with $E$. coli at a multiplicity of infection (MOI) of 100 at different time points. Cell viability is expressed as a percentage compared with the uninfected control cells. Results are means \pm standard deviations (error bars) of triplicate assays.

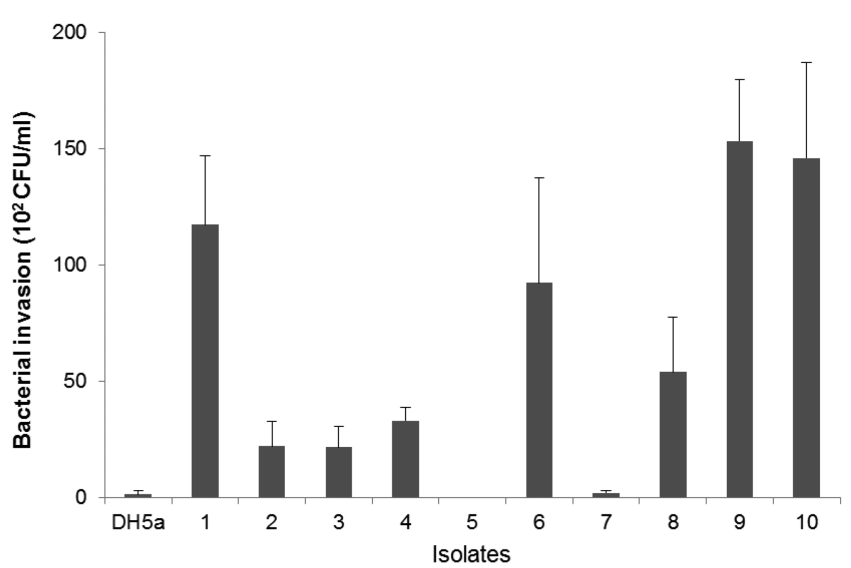

Fig. 3. Invasion abilities of canine uropathogenic E. coli isolates into human T24 bladder epithelial cells.

T24 cells were infected with $E$. coli at a multiplicity of infection (MOI) of 10 for $4 \mathrm{~h}$ and were then incubated for an additional $2 \mathrm{~h}$ in the presence of meropenum. Invasion is expressed as the total number of CFU/ml. Results are means \pm standard deviations (error bars) of three independent assays, each performed in duplicate.

To analyze the cytokine production by T24 cells in response to canine UPEC infection, the levels of IL-6 and IL- 8 released by T24 cells were measured by real-time PCR analysis. The levels of proinflammatory cytokine IL6 mRNA increased 107-fold compared with those in uninfected control cells (Fig. 4A). The levels of neutrophil chemoattractant IL-8 mRNA increased 60-fold compared with those in uninfected control cells (Fig. 4B). IL-6 and IL-8 gene expression levels following bacterial infection increased significantly in cells infected with all canine UPEC isolates compared with those in uninfected control cells $(p<0.001)$.

\section{Discussion}

E. coli is the major causative agent of UTIs in humans and domestic animals [38]. Recent studies suggest that animaloriginating $E$. coli has zoonotic potential for human infections $[10,34]$. Therefore, we investigated not only the characteristics of $10 \mathrm{E}$. coli isolates from dogs with cystitis but also the interaction between the canine UPEC isolates and human bladder epithelial cells.

The interaction between UPEC and the bladder epithelial cells is important during establishment of a UTI [7, 13]. Epithelial cells are the first line of host defense against invading pathogens [9]. In addition, epithelial cells contribute to the initiation of host innate and adaptive immune responses by producing chemokines, cytokines, and antimicrobial peptides [23]. The immune response to UPEC is initiated by bacterial invasion of bladder epithelial cells, which induces the production of proinflammatory cytokines such as IL-6 and IL- 8 and recruits neutrophils to the infection 

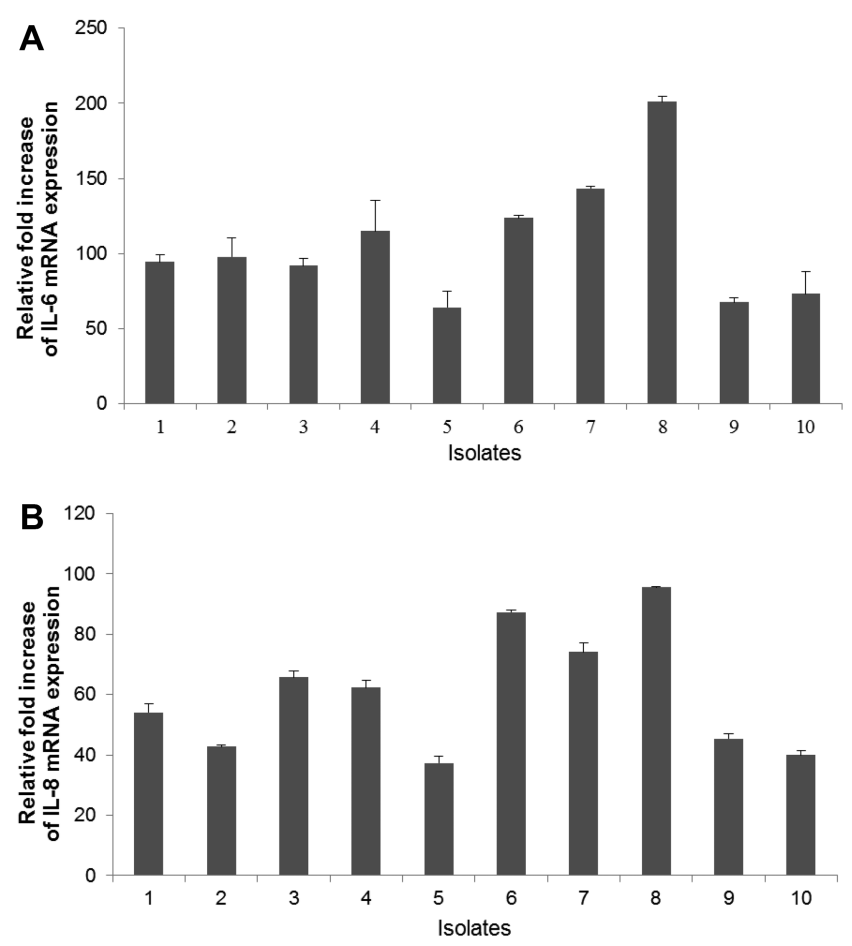

Fig. 4. Human T24 bladder epithelial cell responses to canine uropathogenic $E$. coli isolates.

T24 cells were infected with uropathogenic $E$. coli isolates at a multiplicity of infection (MOI) of 100 for $4 \mathrm{~h}$. Interleukin (IL)-6 (A) and IL-8 (B) mRNA levels were quantified by real-time polymerase chain reaction. The relative levels of the genes corrected by GAPDH were compared with uninfected control cells. All tested $E$. coli isolates significantly stimulated IL-6 and IL-8 mRNA expression compared with control $(P<0.001)$. Results are means \pm standard deviations (error bars) of triplicate assays.

site [17]. Previous studies using murine cystitis models showed that intracellular UPEC can persist within the mouse bladder regardless of antibiotic treatments used to effectively reduce bacterial titers within urine [16]. Several more recent studies have demonstrated that UPEC can persist for many days within host bladder epithelial cells and rapidly multiply intracellularly $[18,24]$. These data suggest that the ability of UPEC to invade bladder epithelial cells plays a critical role during UTI pathogenesis [16].

The ability of UPEC to establish a UTI in the urinary tract is determined by its ability to express surface adhesive structures that facilitate colonization of uroepithelial cells [25]. UPEC expresses various adhesive structures called pili or fimbriae, which mediate adherence to and invasion of uroepithelial cells $[35,37]$. Of these adhesive structures, mannose-sensitive type 1 pili are critical during the establishment of cystitis [25]. In addition to bacterial adherence, several virulence factors such as toxins and iron acquisition systems may contribute to UPEC pathogenicity by facilitating bacterial colonization within host uroepithelial cells and help the bacteria overcome host defenses [32]. We identified the presence of virulence factors in canine
UPEC isolates. Aside from the toxin genes commonly found in UPEC, such as cnfl and $h l y A$, other virulence genes were detected in canine UPEC isolates, including typical UPEC virulence genes such as type $1, \mathrm{P}$, and F1C fimbriae, aerobactin, usp, and the capsule gene. The fimH gene, encoding the type 1 pili, was the most common in the canine UPEC isolates. The $\mathrm{fimH}$-positive isolates also frequently produced other virulence factors, enhancing $E$. coli infectivity. This result demonstrates that type 1 pili is an important contributor to virulence.

Biofilm formation is one of several virulence determinants associated with chronic and recurrent bladder infections $[14,30]$. Biofilms are defined as biological structures developed by microorganisms that promote persistence in the urinary tract by protecting bacteria from the killing activity of host defenses and antibiotics [30]. An important factor during the first steps of biofilm formation is type 1 pili, which aid bacterial adhesion to host epithelial cells [2]. In this study, all isolates showed varying degrees of biofilm formation. Studies reporting the association between biofilm formation and virulence factors have shown different results $[19,33]$. However, no significant correlation was seen between biofilm formation and type 1 pili expression in the present isolates. Thus, it does not seem that type 1 pili are crucial for biofilm formation in UPEC isolates. These results also indicate that urovirulence does not seem to be related to biofilm formation. Recent studies have demonstrated that biofilm formation is associated with asymptomatic $E$. coli bacteriuria and appears to be an important strategy used by these $E$. coli to colonize the urinary tract $[6,14]$.

The ability of bacteria to acquire resistance to antimicrobials is vital for persistence in the urinary tract [3]. The increasing use of antimicrobials is an important factor in the increased frequency of antimicrobial resistance [31]. We showed that the highest resistance was found for ampicillin (75\%), cefazolin $(75 \%)$, and ciprofloxacin $(60 \%)$, whereas the highest susceptibility was seen for imipenem $(100 \%)$, meropenem (100\%), and piperacillin/tazobactam (100\%). Strong biofilm-producing E. coli isolates were less resistant to antimicrobial agents than the weak biofilm-producing E. coli isolates. This result agrees with previous studies showing that biofilm producers are significantly less resistant to antibiotics than non-biofilm producers $[19,30]$. The increase in antimicrobial resistance among E. coli strains seems to be an important determinant in the successful management of infection.

We investigated the ability of canine UPEC isolates to cause a UTI in human bladder epithelial cells. We also examined their ability to induce cytotoxicity in human bladder epithelial cells. All canine UPEC isolates used in this study induced time-dependent cytotoxicity, indicating that bacterial viability is important to cytotoxicity. UPEC firmly adheres and eventually invades bladder epithelial 
cells to establish a UTI [16]. We found that most canine UPEC isolates were able to invade human bladder epithelial cells, with the exception of some noninvasive isolates. This finding indicates that UPEC does not have an absolute host specificity for their entry site. The immune response to UPEC is essential for defense against UTIs [1]. The proinflammatory cytokine IL-6 correlates with disease severity, and neutrophil-attractant chemokine IL-8 mediates the elimination of bacteria during a UTI [11]. In this study, canine UPEC isolates triggered a significant host response in human bladder epithelial cells. In previous studies, bacterial invasion appeared to be a critical factor for enhancing secretion of bladder epithelial cell cytokine production in response to infection $[8,26]$. However, we showed that all canine UPEC isolates strongly stimulated IL-6 and IL-8 secretion by human bladder epithelial cells, regardless of their degree of invasion, and, thus, their mechanism of epithelial responsiveness remains undefined.

In conclusion, we characterized a collection of canine UPEC isolates with respect to antimicrobial-resistant patterns, virulence factors, and biofilm formation and compared these isolates with human clinical isolates examined in previous studies. We demonstrated that canine UPEC isolates induce cytotoxicity, invade human bladder epithelial cells, and stimulate epithelial production of proinflammatory cytokines. Therefore, these findings suggest that canine UPEC, rather than dog-specific pathogens, could represent a zoonotic risk. A limitation of this study was the relatively small number of $E$. coli isolates used; thus, the results will require further confirmation. Further studies will be needed to investigate the detailed mechanisms mediating the interaction between canine UPEC and human bladder epithelial cells.

\section{REFERENCES}

1. Albiger, B., S. Dahlberg, B. Henriques-Normark, and S. Normark. 2007. Role of the innate immune system in host defence against bacterial infections: Focus on the Toll-like receptors. J. Intern. Med. 261: 511-528.

2. Anderson, G. G., K. W. Dodson, T. M. Hooton, and S. J. Hultgren. 2004. Intracellular bacterial communities of uropathogenic Escherichia coli in urinary tract pathogenesis. Trends Microbiol. 12: 424-430.

3. Blango, M. G. and M. A. Mulvey. 2010. Persistence of uropathogenic Escherichia coli in the face of multiple antibiotics. Antimicrob. Agents Chemother. 54: 1855-1863.

4. Clinical and Laboratory Standards Institute. 2004. Performance standards for antimicrobial susceptibility testing: Fourteenth informational supplement. M100-S14. National Committee for Clinical Laboratory Standards, Wayne, PA.

5. Farshad, S., R. Ranjbar, A. Japoni, M. Hosseini, M. Anvarinejad, and R. Mohammadzadegan. 2012. Microbial susceptibility, virulence factors, and plasmid profiles of uropathogenic Escherichia coli strains isolated from children in Jahrom, Iran. Arch. Iran. Med. 15: $312-316$.

6. Hancock, V., L. Ferrieres, and P. Klemm. 2007. Biofilm formation by asymptomatic and virulent urinary tract infectious Escherichia coli strains. FEMS Microbiol. Lett. 267: 30-37.

7. Hilbert, D. W., K. E. Pascal, E. K. Libby, E. Mordechai, M. E. Adelson, and J. P. Trama. 2008. Uropathogenic Escherichia coli dominantly suppress the innate immune response of bladder epithelial cells by a lipopolysaccharide-and Toll-like receptor 4independent pathway. Microbes Infect. 10: 114-121.

8. Hornef, M. W., M. J. Wick, M. Rhen, and S. Normark. 2002. Bacterial strategies for overcoming host innate and adaptive immune responses. Nat. Immunol. 3: 1033-1040.

9. Iwasaki, A. and R. Medzhitov. 2004. Toll-like receptor control of the adaptive immune responses. Nat. Immunol. 5: 987-995.

10. Jakobsen, L., P. Garneau, G. Bruant, J. Harel, S. Olsen, L. Porsbo, A. Hammerum, and N. Frimodt-Møller. 2012. Is Escherichia coli urinary tract infection a zoonosis? Proof of direct link with production animals and meat. Eur. J. Clin. Microbiol. Infect. Dis. 31: 1121-1129.

11. Jantausch, B. A., R. O'Donnell, and B. L. Wiedermann. 2000. Urinary interleukin- 6 and interleukin- 8 in children with urinary tract infection. Pediatr. Nephrol. 15: 236-240.

12. Johnson, J. R., A. L. Stell, P. Delavari, A. C. Murray, M. Kuskowski, and W. Gaastra. 2001. Phylogenetic and pathotypic similarities between Escherichia coli isolates from urinary tract infections in dogs and extraintestinal infections in humans. $J$. Infect. Dis. 183: 897-906.

13. Kau, A. L., D. A. Hunstad, and S. J. Hultgren. 2005. Interaction of uropathogenic Escherichia coli with host uroepithelium. Curr. Opin. Microbiol. 8: 54-59.

14. Mabbett, A. N., G. C. Ulett, R. E. Watts, J. J. Tree, M. Totsika, C. Y. Ong, et al. 2009. Virulence properties of asymptomatic bacteriuria Escherichia coli. Int. J. Med. Microbiol. 299: 5363.

15. Marklund, B. I., J. M. Tennent, A. H. Garcia, M. Baga, F. Lindberg, W. Gaastra, and S. Normak. 1992. Horizontal gene transfer of the Escherichia coli pap and prs pili operons as a mechanism for the development of tissue-specific adhesive properties. Mol. Microbiol. 6: 2225-2242.

16. Martinez, J. J., M. A. Mulvey, J. D. Schilling, J. S. Pinkner, and S. J. Hultgren. 2000. Type 1 pilus-mediated bacterial invasion of bladder epithelial cells. EMBO. J. 19: 2803-2812.

17. Mulvey, M. A. 2002. Adhesion and entry of uropathogenic Escherichia coli. Cell Microbiol. 4: 257-271.

18. Mulvey, M. A., J. D. Schilling, and S. J. Hultgren. 2001. Establishment of a persistent Escherichia coli reservoir during the acute phase of a bladder infection. Infect. Immun. 69: 4572-4579.

19. Naves, P., G. del Prado, L. Huelves, M. Gracia, V. Ruiz, J. Blanco, et al. 2008. Correlation between virulence factors and in vitro biofilm formation by Escherichia coli strains. Microb. Pathog. 45: 86-91.

20. Ngamwongsatit, P., P. P. Banada, W. Panbangred, and A. K. Bhunia. 2008. WST-1-based cell cytotoxicity assay as a substitute for MTT-based assay for rapid detection of toxigenic Bacillus species using CHO cell line. J. Microbiol. Methods 73: 211-215. 
21. Ohkusa, T., T. Yoshida, N. Sato, S. Watanabe, H. Tajiri, and I. Okayasu. 2009. Commensal bacteria can enter colonic epithelial cells and induce proinflammatory cytokine secretion: A possible pathogenic mechanism of ulcerative colitis. J. Med. Microbiol. 58: $535-545$.

22. Russo, T. A. and J. R. Johnson. 2003. Medical and economic impact of extraintestinal infections due to Escherichia coli: Focus on an increasingly important endemic problem. Microbes Infect. 5: 449-456.

23. Scherberich, J. E. and A. Hartinger. 2008. Impact of Toll-like receptor signalling on urinary tract infection. Int. J. Antimicrob. Agents 31: 9-14.

24. Schilling, J. D. and S. J. Hultgren. 2002. Recent advances into the pathogenesis of recurrent urinary tract infections: The bladder as a reservoir for uropathogenic Escherichia coli. Int. J. Antimicrob. Agents 19: 457-460.

25. Schilling, J. D., S. M. Martin, D. A. Hunstad, K. P. Patel, M. A. Mulvey, S. S. Justice, et al. 2003. CD14- and Toll-like receptordependent activation of bladder epithelial cells by lipopolysaccharide and type 1 piliated Escherichia coli. Infect. Immun. 71: 14701480.

26. Schilling, J. D., M. A. Mulvey, C. D. Vincent, R. G. Lorenz, and S. J. Hultgren. 2001. Bacterial invasion augments epithelial cytokine responses to Escherichia coli through a lipopolysaccharidedependent mechanism. J. Immunol. 166: 1148-1155.

27. Sivick, K. E. and H. L. Mobley. 2010. Waging war against uropathogenic Escherichia coli: Winning back the urinary tract. Infect. Immun. 78: 568-585.

28. Smith, J. L., P. M. Fratamico, and N. W. Gunther. 2007. Extraintestinal pathogenic Escherichia coli. Foodborne Pathog. Dis. 4: 134-163.
29. Song, J. and S. Abraha. 2008. Innate and adaptive immune responses in the urinary tract. Eur. J. Clin. Invest. 38: 21-28.

30. Soto, S., A. Smithson, J. Martinez, J. Horcajada, J. Mensa, and J. Vila. 2007. Biofilm formation in uropathogenic Escherichia coli strains: Relationship with prostatitis, urovirulence factors and antimicrobial resistance. J. Urol. 177: 365-368.

31. Thompson, M. F., A. L. Litster, J. L. Platell, and D. J. Trott. 2011. Canine bacterial urinary tract infections: New developments in old pathogens. Vet. J. 190: 22-27.

32. Tiba, M. R., T. Yano, and D. S. Leite. 2008. Genotypic characterization of virulence factors in Escherichia coli strains from patients with cystitis. Rev. Inst. Med. Trop. Sao Paulo 50: 255-260.

33. Van Houdt, R. and C. W. Michiels. 2005. Role of bacterial cell surface structures in Escherichia coli biofilm formation. Res. Microbiol. 156: 626-633.

34. Wasteson, Y. 2001. Zoonotic Escherichia coli. Acta Vet. Scand. Suppl. 95: 79-84.

35. Wiles, T. J., R. R. Kulesus, and M. A. Mulvey. 2008. Origins and virulence mechanisms of uropathogenic Escherichia coli. Exp. Mol. Pathol. 85: 11-19.

36. Wohlgemuth, S., D. Haller, M. Blaut, and G. Loh. 2009. Reduced microbial diversity and high numbers of one single Escherichia coli strain in the intestine of colitic mice. Environ Microbiol. 11: 1562-1571.

37. Xia, X., J. Meng, P. F. McDermott, and S. Zhao. 2011. Escherichia coli from retail meats carry genes associated with uropathogenic Escherichia coli, but are weakly invasive in human bladder cell culture. J. Appl. Microbiol. 110: 1166-1176.

38. Yamamoto, S. 2007. Molecular epidemiology of uropathogenic Escherichia coli. J. Infect. Chemother. 13: 68-73. 